\title{
Inflammatory Pseudotumors in Multiple Organs Associated with Elevated Serum IgG4 Level: Recovery by Only a Small Replacement Dose of Steroid
}

\author{
Hiroto Tsuboi ${ }^{1}$, Shigeko Inokuma ${ }^{1}$, Keigo Setoguchi ${ }^{1}$, Sumitomo Shuji ${ }^{1}$, Noboru Hagino ${ }^{1}$, \\ Yoshiaki Tanaka ${ }^{1}$, Nozomi Yoshida ${ }^{1}$, Tsunekazu Hishima ${ }^{2}$ and Terumi Kamisawa ${ }^{3}$
}

\begin{abstract}
A 62-year-old man developed a fever, fatigue, anorexia and arthralgia. Central hypocorticoidism and central hypothyroidism were observed, and a low serum antidiuretic hormon level without symptoms of diabetes insipidus, as well. Images showed swelling of pituitary stalk, mediastinal and hilar lymphnodes and pancreas, pulmonary infiltrates and retroperitoneal mass. Serum CRP level was $20.6 \mathrm{mg} / \mathrm{dL}$, and IgG4 level was 292 $\mathrm{mg} / \mathrm{dL}$. Lung biopsy revealed pseudotumor containing IgG4-positive plasmacytes, and obliterative vasculitis both in arterioles and venules. These features were similar to those of reported IgG4-related autoimmune disease. However, replacement steroid therapy for hypocorticoidism brought about almost complete recovery except that diabetes insipidus got apparent. This is the first report on the efficacy of only a small dose of steroid, and on features of pituitary stalk involvement and central hypocorcicoidism.
\end{abstract}

Key words: IgG4, pseudotumor, hypocorticoidism, steroid replacement

(Inter Med 47: 1139-1142, 2008)

(DOI: 10.2169/internalmedicine.47.0887)

\section{Introduction}

Recently, autoimmune pancreatitis has been the focus of interest in pancreatology. Autoimmune pancreatitis has some unique features; irregular narrowing of the main pancreatic duct, an elevated serum IgG4 level, and good response to steroid treatment. Moreover, it has been reported that patients with autoimmune pancreatitis had simultaneously extra-pancreatic lesions which contained IgG4-positive plasmacytes infiltration (1).

We treated a patient with autoimmune pancreatitis having central hypocorticoidism and hypothyroidism, pseudotumors in the pituitary stalk, in lungs, and in retroperitoneum. The observations in this case would add new features to those already reported for the proposed disease entity of IgG4related generalized disease.

\section{Case Report}

A 62-year-old man developed a fever higher than $38^{\circ} \mathrm{C}$, fatigue, anorexia and body weight loss, and joint stiffness. Six months later, he visited our hospital, and adrenal insufficiency was revealed.

Central hypocorticoidism was the diagnosis, as serum adrenocorticotropic hormone (ACTH) level was $13.3 \mathrm{pg} / \mathrm{mL}$ (normal range; $9-52 \mathrm{pg} / \mathrm{mL}$ ), and cortisol level $2.9 \mu \mathrm{g} / \mathrm{dL}$ $(3.8-18.4 \mu \mathrm{g} / \mathrm{dL})$ that was increased to $20.0 \mu \mathrm{g} / \mathrm{dL}$ after ACTH stimulation. Central hypothyroidism was also observed, as serum free-T3, free-T4 and thyroid-stimulating hormone (TSH) levels were $1.7 \mathrm{pg} / \mathrm{mL}(2.0-3.8 \mathrm{pg} / \mathrm{mL}), 0.6$ $\mathrm{ng} / \mathrm{mL}(0.7-1.5 \mathrm{ng} / \mathrm{mL})$ and $0.34 \mu \mathrm{U} / \mathrm{mL}(0.40-4.8 \mu \mathrm{U} / \mathrm{mL})$, respectively. The serum antidiuretic hormone $(\mathrm{ADH})$ level was as low as $0.40 \mathrm{pg} / \mathrm{mL}$, the daily urine volume was $0.5-1$ $\mathrm{L}$, the plasma and the urine osmolality were 254 and 373

${ }^{1}$ Department of Allergy and Immunological Diseases, Tokyo Metropolitan Komagome Hospital, Tokyo, ${ }^{2}$ Department of Pathology, Tokyo Metropolitan Komagome Hospital, Tokyo and ${ }^{3}$ Department of Internal Medicine, Tokyo Metropolitan Komagome Hospital, Tokyo

Received for publication January 5, 2008; Accepted for publication March 5, 2008

Correspondence to Dr. Hiroto Tsuboi, Hiroto-Tsuboi@md.tsukuba.ac.jp 

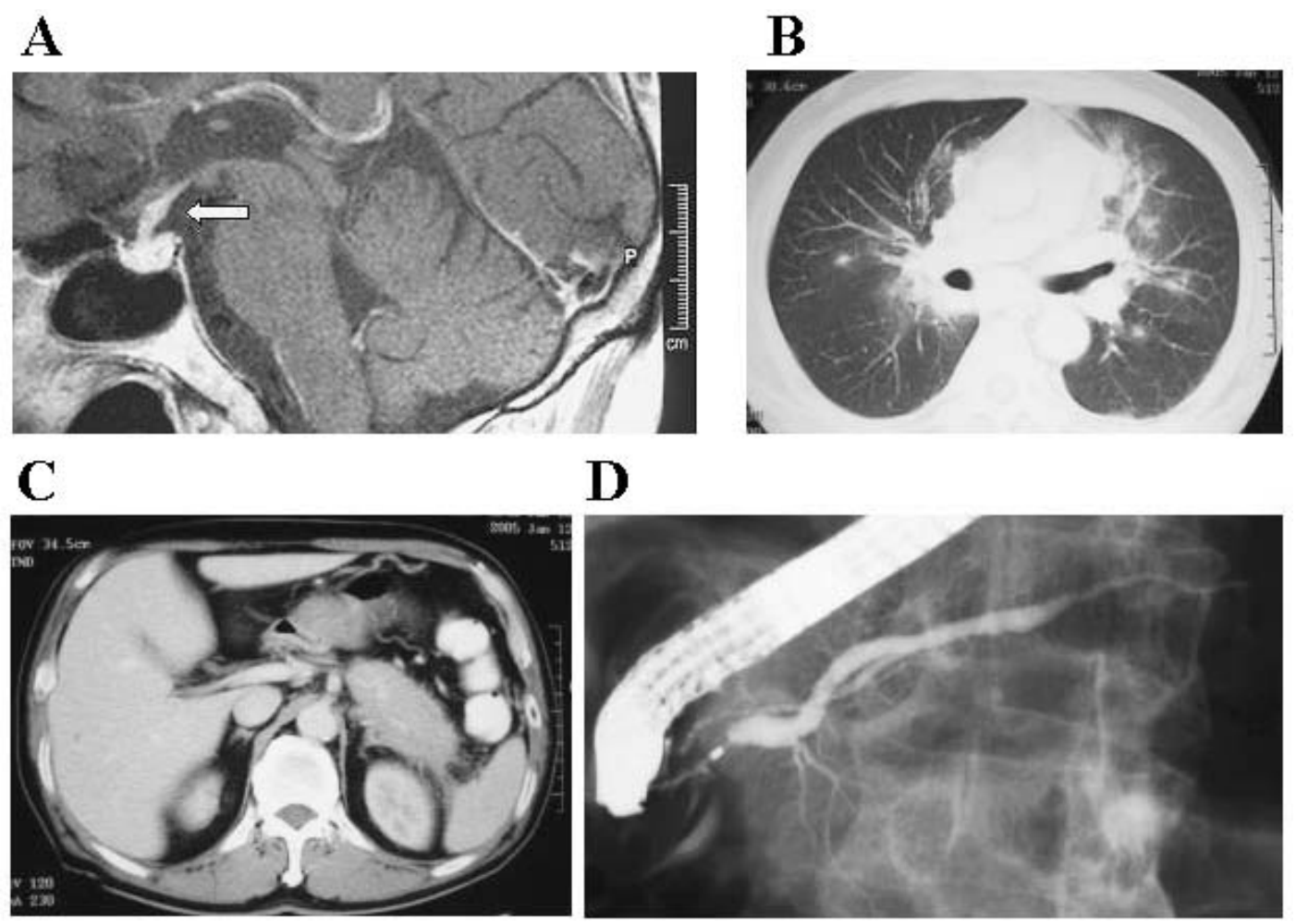

\section{D}

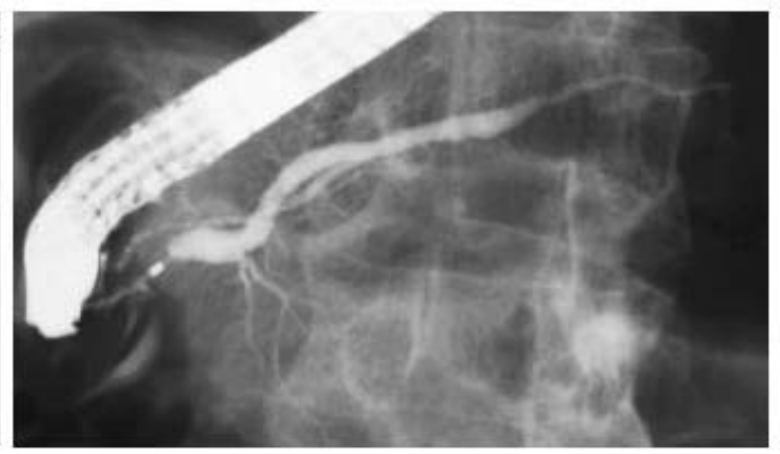

Figure 1. A: Brain magnetic resonance image demonstrated enlarged pituitary stalk and high intensity on T1WI with contrast enhancement (arrow head). B: Thoracic computed tomography (CT) demonstrated bilateral pulmonary infiltrates and mediastinal and hilar lymph node swelling. C: Abdominal CT demonstrated diffusely swollen pancreas. D: Endoscopic retrograde cholangiopancreatography (ERCP) showed segmental irregular narrowing of the main pancreatic duct in the tail.

$\mathrm{mOsm} / \mathrm{kg}$, respectively, and the serum sodium and potassium levels were $123 \mathrm{mEq} / \mathrm{L}(138-144 \mathrm{mEq} / \mathrm{L})$ and 5.3 $\mathrm{mEq} / \mathrm{L}$ (3.5-4.7 $\mathrm{mEq} / \mathrm{L})$, respectively.

The serum CRP level was $20.6 \mathrm{mg} / \mathrm{dL}(0-0.3 \mathrm{mg} / \mathrm{dL})$. The serum levels of $\operatorname{IgG}, \operatorname{IgA}$, IgM, and IgG4 were 1990, 400, 128 , and $292 \mathrm{mg} / \mathrm{dL}(870-1,700,110-410,35-220$, and $<135$ $\mathrm{mg} / \mathrm{dL}$ ), respectively. The serum $\beta_{2}$-microglobulin level was $6.2 \mathrm{mg} / \mathrm{dL}(0.9-1.9 \mathrm{mg} / \mathrm{dL})$, without increase in levels of BUN or creatinine. Liver and bile duct enzymes and amylase levels were within the normal ranges. Arterial blood gas analysis under room air respiration showed $7.43 \mathrm{pH}, 65$ $\mathrm{mmHg} \mathrm{PaO}_{2}, 35 \mathrm{mmHg} \mathrm{PaCO}_{2}, 23 \mathrm{mEq} / \mathrm{L} \mathrm{HCO}_{3}^{-}$, and -1.0 $\mathrm{mEq} / \mathrm{L} \mathrm{BE}$. Routine examinations for autoantibodies showed negative results.

Brain magnetic resonance imaging (MRI) revealed an enlarged pituitary stalk (Fig. 1A).

Chest images showed bilateral pulmonary infiltrates, and mediastinal and hilar lymph node swelling (Fig. 1B). Lung specimen of left upper lobe obtained by video-assisted thoracic surgery showed an inflammatory pseudotumor characterized by fibrosis with proliferation of fibroblasts and myofibroblasts. Lymphocytes, histiocytes, and plasmacytes infiltrated into the alveolar lumens and walls. Obliterative vasculitides in both venules and arterioles with lymphocyte and plasmacyte infiltration were observed, and small and non- necrotizing granulomas were sparsely (Figs. 2A, 2B). The infiltrating lymphocytes were mostly CD3-positive, although CD20-positive B cells were also observed to a lesser extent. IgG- and IgA-positive plasmacytes predominated, without clear $\kappa$ or $\lambda$ light chain preference, and $23 \%$ of IgG-positive plasmacytes were IgG4-positive (Fig. 2C).

Either CT or echography of the abdomen revealed diffusely swollen pancreas (Fig. 1C). Endoscopic retrograde cholangiopancreatography (ERCP) showed segmental irregular narrowing of the main pancreatic duct in the tail (Fig. 1D). Abdominal CT also revealed left hydronephrosis with a mass having a soft tissue density around the pelvis. Urinary cytology showed no abnormality.

Although sialoscintigraphy showed mild left parotid gland dysfunction, neither salivary gland swelling, xerostomia, nor xerophthalmia was observed. Biopsy of labial salivary glands showed no inflammatory change.

Antibiotic therapy with ciprofloxacin (CPFX) for a week and non steroidal anti-inflammatory drug (NSAID) were not effective in fever and fatigue, but serum CRP level decreased to $7.4 \mathrm{mg} / \mathrm{dL}$. To treat the hypocorticoidism, $30 \mathrm{mg} /$ day of replacement cortisol was started, achieving rapid and complete recovery from adrenal insufficiency. After a month of the replacement, the serum levels of cortisol, free-T3, free-T4, and TSH returned to the normal levels. Urine vol- 


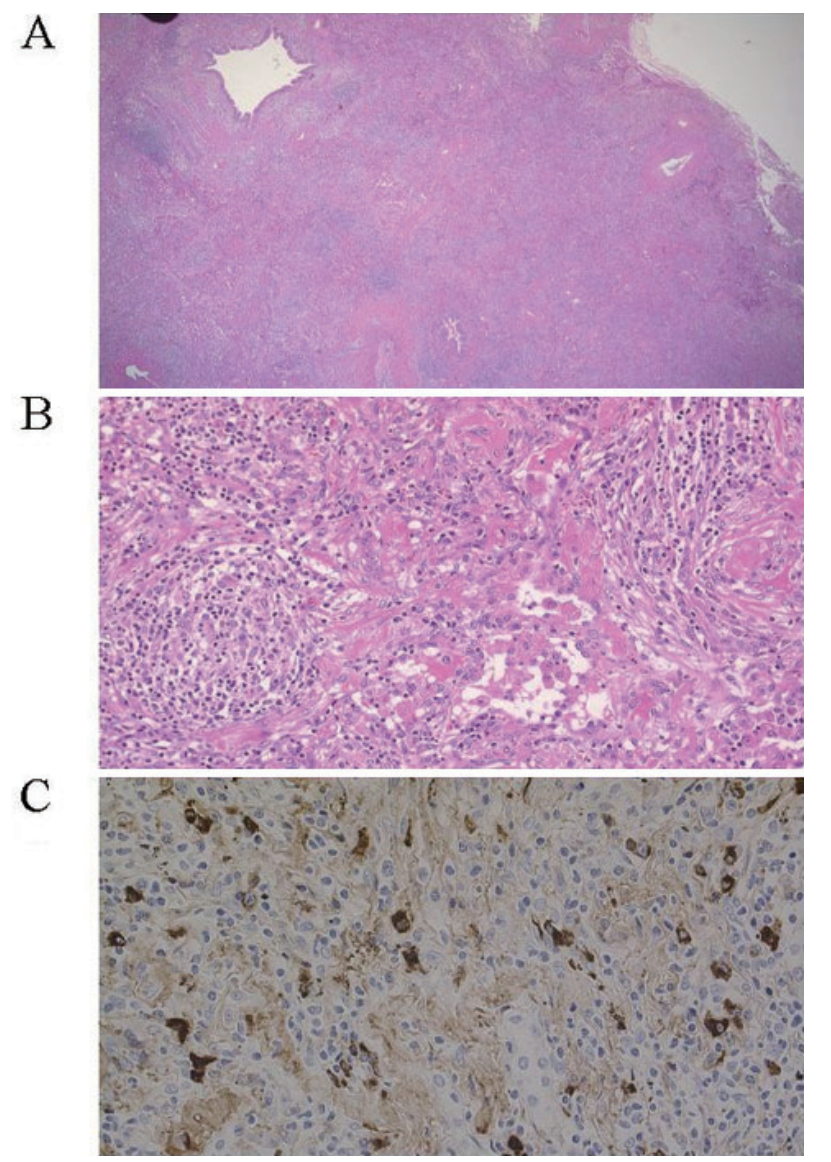

Figure 2. A and B: Lung specimen containing an inflammatory pseudotumor showed fibrosis with infiltration of lymphocytes, histiocytes, and plasmacytes. C: Immunohistochemically, many of the IgG-positive plasmacytes were IgG4 positive.

ume increased to 5-6 L/day. Serum sodium level increased to $147 \mathrm{mEq} / \mathrm{L}$, plasma osmolality increased to $304 \mathrm{mOsm} /$ $\mathrm{kg}$, and urine osmolality decreased to $114 \mathrm{mOsm} / \mathrm{kg}$. Serum ADH level remained lower than $0.30 \mathrm{pg} / \mathrm{mL}$.

Brain MRI showed the still enlarged pituitary stalk one month after the steroid replacement, but the size of pituitary stalk diminished slightly. The pulmonary infiltrates disappeared, mediastinal and hilar lymph node swelling subsided, and $\mathrm{PaO}_{2}$ returned to normal. The retroperitoneal mass and the swollen pancreas reduced in size. Serum CRP level decreased to $0.7 \mathrm{mg} / \mathrm{dL}$ within seven days of sampling interval after the replacement steroid therapy. Serum IgG and IgG4 levels also decreased to 1,500 and $130 \mathrm{mg} / \mathrm{dL}$, respectively. Serum $\beta_{2}$-microglobulin level decreased to $3.1 \mathrm{mg} / \mathrm{dL}$. The patient has been well for eight months only with cortisol replacement (Fig. 3).

\section{Discussion}

Recently, so-called autoimmune pancreatitis has been the focus of interest in pancreatology, although usually observed or measured autoantibodies including rheumatoid factor (RF), anti-smooth muscle antibody, or antimitochondrial antibody are negative in most cases, some disease-specific

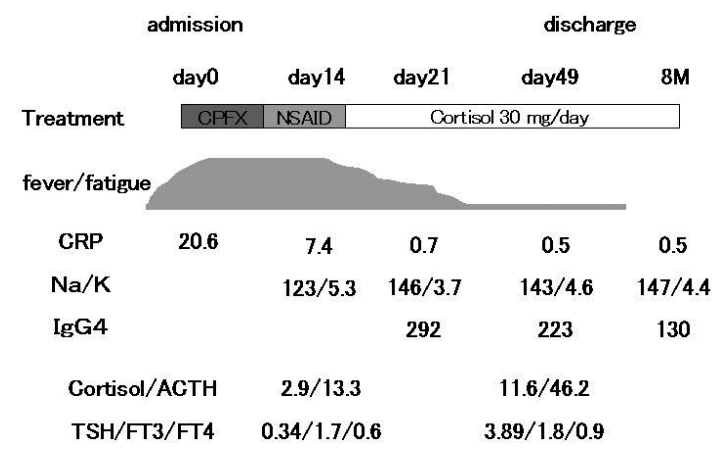

Figure 3. Clinical Course

autoantibodies to lactoferrin or carbonic anhydrase are detected (2). In it, swelling of the pancreas, irregular narrowing of the main pancreatic duct, and an elevated serum IgG4 level are commonly observed (3). In tissue specimen, lympho-plasmacytic infiltration, particularly of IgG4-positive plasmacytes, and interstitial fibrosis with pancreatic acinar atrophy is observed (4). Patients with these features sometimes have simultaneously retroperitoneal fibrosis, sclerosing cholangitis, lymphadenopathy, sclerosing sialadenitis, or hypothyroidism (5). For including all these features, Kamisawa et al proposed a new disease concept of IgG4-related autoimmune disease, emphasizing the importance of detecting IgG4-positive plasmacytes in tissue specimens (1). Hans and Roos reported possible involvement of pituitary gland and lungs in this disease (6).

The presented case had very similar graphical findings of the pancreas to those of reported autoimmune pancreatitis, and additionally a new feature of both central hypocorticoidism and central hypothyroidism, and biopsy-proven pseudotumor in the lungs.

The lung specimen showed an inflammatory pseudotumor containing IgG4-positive plasmacytes. An inflammatory pseudotumor is characterized histologically by the irregular proliferation of myofibroblasts intermixed with inflammatory cells, mainly lymphocytes and plasmacytes. It is regarded to be a heterogeneous disease and is subcategorized histologically into (a) fibrohistiocytic type, (b) plasma cell granuloma type, (c) largely sclerosed or fibrosed type, (d) hypocellular fibrous type, and (e) myxoid/vascular type (7). Our patient's pseudotumor in the lung corresponds to the plasma cell granuloma type, showing abundant plasmacytes and lymphocytes. In contrast to that the infiltration is mainly in the venous wall in autoimmune pancreatitis, the infiltration was observed in obliterative vasculitides of both venules and arterioles. Zen et al reported an inflammatory pseudotumor of the plasma cell granuloma type of the lung, that was similar to the autoimmune pancreatitis except that obliterative arteritis was found in addition to phlebitis (8).

Autoimmune pancreatitis is usually treated with a daily $30-40 \mathrm{mg}$ of prednisolone, which alleviates the swelling of the pancreas, and normalizes serum IgG4 level. In our patient, only a much lesser dose of replacement steroid cured 
either the central hypocorticoidism and hypothyroidism, the pseudotumors in the lungs, swollen lymph nodes and pancreas, or the retroperitoneal mass. Some possible interpretations on why replacement steroid therapy alone cured the disease include that replacement steroid might have triggered a spontaneous remission, as has been reported in a case of autoimmune pancreatitis (9), or that small dose might be effective as the therapeutic regimen. Another possibility is that hypocorticoidism might be involved in the development of IgG4-related lesions of this patient. It was reported that patients with polymyalgia rheumatica (PMR) might have hypoactivation in the hypothalamic-pituitaryadrenal (HPA) axis (10). Hypocorticoidism might influence the systemic immune response, and finally resulted in the development of IgG4-related autoimmune disease the same as PMR. Normalizing the cortisol level might improve the systemic immune system.

Although enlarged pituitary stalk persisted after the steroid replacement, the size of pituitary stalk diminished slightly. Therefore, this lesion might be involved in IgG4related autoimmune disease, and the cause of enlarged stalk might be inflammatory pseudotumor the same as other or- gans.

After the therapy, the urine volume increased much, and plasma osmolality increased and urine osmolality decreased. The serum ADH level was still low; and the disease consistent with diabetes insipidus got apparent. On his admission, diabetes insipidus would have been submerged, maybe being masked by central hypocorticoidism that disturbed water diuresis. Then, replacement steroid induced water diuresis, resulting in apparent diabetes insipidus, that was still observed ten months later. In contrast to the normalized serum ACTH and cortisol levels, low serum ADH level and the enlarged pituitary stalk remained. Follow-up of his clinical course will be needed.

In summary, the new observations in the presented case included that pituitary involvement caused either central hypocorticoidism and hypothyroidism or diabetes insipidus, and that both arterioles and venules in the lung were involved. To the best of our knowledge, this is the first report on that only replacement steroid brought about almost complete recovery from multiorgan involvement and a high serum IgG4 level.

\section{References}

1. Kamisawa T, Funata N, Hayashi Y, et al. A new clinicopathological entity of IgG4-related autoimmune disease. J Gastroenterol 38: 982-984, 2003.

2. Okazaki K, Uchida K, Ohana M, et al. Autoimmune-related pancreatitis is associated with autoantibodies and a Th1/Th2-type cellular immune response. Gastroenterology 118: 573-581, 2000.

3. Hamano H, Kawa S, Horiuchi A, et al. High serum IgG4 concentrations in patients with sclerosing pancreatitis. $\mathrm{N}$ Engl $\mathrm{J}$ Med 344: 732-738, 2001.

4. Kamisawa T, Fuata N, Hayashi Y, et al. Close relationship between autoimmune pancreatitis and multifocal fibrosclerosis. Gut 52: 683-687, 2003.

5. Komatsu K, Hamano H, Ochi Y, et al. High prevalence of hypothyroidism in patients with autoimmune pancreatitis. Dig Dis Sci 50: 1052-1057, 2005.

6. Hans J, Roos M. Multiple pseudotumors in IgG4-associated multifocal systemic fibrosis. Ann Intern Med 141: 896-897, 2004.

7. Travis WD, Colby TV, Koss MN, Rosado-de-Christenson ML,
Muller NL, King TE Jr. Miscellaneous disease of uncertain etiology. In: Atlas of Nontumor Pathology. Non-neoplastic Disorders of the Lower Respiratory Tract. 1st ed. King DW, Ed. American Registry of Pathology and Armed Forced Institute of Pathology, Washington DC, 2002: 857-900.

8. Zen Y, Kitagawa $\mathrm{S}$, Minato $\mathrm{H}$, et al. IgG4-positive plasma cells in inflammatory pseudotumor (plasma cell granuloma) of the lung. Human Pathol 36: 710-717, 2005.

9. Ozden I, Dizdaroglu F, Poyanli A, Emre A. Spontaneous regression of a pancreatic head mass and biliary obstruction due to autoimmune pancreatitis. Pancreatology 5: 300-303, 2005.

10. Demir H, Tanriverdi F, Ozogul N, et al. Evaluation of the hypothalamic-pituitary-adrenal axis in untreated patients with polymyalgia rheumatica and healthy controls. Scand J Rheumatol 35: 217-223, 2006.

(C) 2008 The Japanese Society of Internal Medicine http://www.naika.or.jp/imindex.html 